well have died down before the glandular enlargement appears That this enlargement will persist long after the secondaries have so disappeared is quite likely when the structure of the glands is considered, for it is evident that after toleration has been acquired and the microbes encapsuled and destroyed the phagocytes will regain the circulation much more readily from the cutaneous lesions than from the recesses of the glands. The pigmentation of the secondary lesions must, I think, be due to the local action of the toxine on the red corpuscles, just as general anxmia results from its accumulation in the circulation.

(To be continued.)

\section{THE REFLEX INFLUENCE OF ALVEOLAR LESIONS ON THE VOCAL CORDS.}

BY W. R. TUCK, L.D.S. R.C.S. ENG.,

LA'TE BONORARY DENTAL BURGEON TO THE TRURO HOSPITAL.

ONE who has been engaged in the active pursuit of dental surgery for a considerable time can scarcely fail to have met with strange and mysterious cases which in diagnosis and treatment baffle the efforts of the most experienced and skilful practitioner. When commencing this article it was my intention to confine the subject to that of neuralgia in its almost endless and protean forms. A unique manifestation of diseased action lately brought under my notice has, however, decided me to deviate from my original intention; I have therefore to introduce my subject metaphorically in order that it may be more clearly understood by the readers of THE LANCET.

If we take the whole range of musical sounds as exemplified, for instance, in the violin, and find them all in point of tone and quality to harmonise, we then pronounce such an instrument to be of a perfect type and its commercial value almost fabulous. It is not unusual to hear of such a sum as $£ 2000$ being paid for an instrument of that description. I was at one time intimately acquainted with a gentleman who bad made the theory of music a profound study for many years. Moreover, he was an advanced mathematician and probably made millions of figures in his geometrical calculations of proportion in the different parts making up the entirety of the instrument. His knowledge of acoustics was also considerable, and as the financial position of this gentleman was equal to the enlightenment of his mind he spared no expense in providing for experiments, in the hope of discovering the true and definite principle on which al instruments of this class could be accurately constructed according to the Amati or Stradivarius method. I was on one occasion invited to his house to see a violin he bad recently purchased in London and for which he had paid £30. It must not be imagined that the instrument commanded that price for its excellence-just the reverse, for the dealer assured this devoted amateur that it had been used in the Italian opera orchestra for a considerable time, but had suddenly failed in its tone. This fact excited the curiosity of my friend and strengthened his desire to purchase it that he might avail himself of the opportunity to examine the make and shape in a critical manner in the endeavour to find the cause of failure. He commenced by first removing the cover, and on minute examination of that part it was found that a worm had eaten a small hole in the bass bar. This discovery was made known to the vendor and the violin returned with instructions for a renewal of the defective part. When that was done the instrument was restored to its original state and value. In all the intricacies and mysterious working of the human system diagnosis is at all times difficult and successful treatment no less so. I have lately met with a case in practice which seems so analogous to the one just described, although in two different natures, that a narration of it may not be uninteresting.

A clergyman in endeavouring to utter the letter $h$ set up a spasmodic action of the vocal cord which took him a few seconds to recover from ere he could proceed with bis discourse. This remarkable affection gave rise to much speculation among the members of his congregation as to the cause. Within the past few months an opportunity has been afforded me for an oral examination, and having noticed a great deflection in the right inferior maxilla where the first molar and second bieuspie were formerly situated I interrogated him as to the cause. He informed me that these teeth had been extracted by a non-qualified man, who bad removed a large portion of the jaw with them; so much so, indeed, as to injure both the nerve and artery -in the first instance interfering seriously with the neurotic force and in the second disturbing the arterial current. It instantly occurred to my mind that this terrible mischief was the cause of his lamentable malady produced by reflex action on the particular cord; there can be little doubt that the damaged part described had originated the affliction from which he suffered and with little chance of amelioration. Here we have evidence of a bungling mutilation by a non-competent operator, with the unhappy result of destroying the best prospects of a useful life. Truro.

\section{A RECORD OF THE DEATHS OCCURRING AMONGST 400 ADOLESCENTS BETWEEN} JAN. 1sT, 1871, AND DEC. 31st, 1895.

BY CLEMENT DUKES, M.D., B.S. LOND., PHYSICIAN TO RUGBY SCHOOL AND SHNIOR PHYSICIAN TO RUGBY HOSPITAL.

IN continuation of my three papers which appeared in The LANcet of Feb. 15th, March 28th, and May 2nd, 1896, I am able, by the courtesy of the present head-master of Rugby, who is very keen on all questions relating to the health of the school, to place before the profession an account of our mortality during the twenty-five years com mencing Jan. 1st, 1871, and terminating Dec. 31st, 1895 During this period the average number of boarders has been 403. The ages range between thirteen and nineteen years. There are eight months spent at school and four months passed at home each year. The deaths during term, therefore, ought to be at least twice the number of those occurring during the vacation, while if allowance be made for the aggregation of so many young people the proportion should be still greater.

\section{1.-Deaths arising DURIng Term.}

1. Pneumonia - A case occurred in March, 1875, and deat took place between the fifth and seventh days, as usual, frow failure of the heart's action.

2. Pleurisy.-A case appeared in June, 1877, and death took place at the end of the fifth week suddenly from syncope owing to pleuritic effusion. In those days it was a disputed point as to the value of early tapping. Had this case arisen a year or two later paracentesis would have taken place early before tension occurred and probably a life have been saved.

3. Scarlet fever.-A case occurred in March, 1881, and although it was a mild type of fever death took place on the fifth day. I believe that the mother and four children in the same family had previously died from scarlet fever.

4. Diphtheria.-A case arose in July, 1883, and death took place from exhaustion. The lad was a great naturalist, and had been searching for some of his treasures in the black mud of a ditch, of which his nails were full.

5. Typhoid fever. - This case occurred in December, 1889, and death arose from perforation on the twenty-fourth day. It originated from eating oysters which were sent as a present from home, and which had come from the mouth of the Liffey or of the Mersey.

6. Cerebro-spinal meningitis. - This case occurred in November, 1893, at the very onset of an attack of influenza and death took place on the third day.

7. Death while running.--This took place in November, 1892, during a run of about three miles, from disintegration of the blood. The runs are now so safeguarded and classified according to age and physique as to be within the compass of all healthy boys, who can but be benefited by participating in them.

8. Peritonitis.-This case occurred suddenly, after a day or two's illness, in July, 1894, and arose in all probability 